\title{
Actualidad del relativismo cultural
}

\author{
Nicolás Sánchez Durá
}

Este ensayo tiene tres propósitos. En primer lugar, propone examinar las relaciones entre etnocentrismo y relativismo. El etnocentrismo puede tomar tres formas distintas: a saber, la de una universalidad impostada, la del exotismo y la de un particularismo narcisista exacerbado. El relativismo cultural es una postura que asume la inconmensurabilidad de los conceptos y valores que deben ser considerados como válidos dentro de las imágenes del mundo definidas. En segundo lugar, se argumenta que el etnocentrismo es una posición infundada y moralmente desastrosa. En tercer lugar, se sostiene que el relativismo cultural en su versión moderada puede servir de guía a los antropólogos sociales: les enseña la tolerancia y el escepticismo acerca de los valores de su propia cultura.

PALABRAS CLAVE: etnocentrismo, relativismo, inconmensurabilidad, culturas, imágenes del mundo

\section{The Pertinence of Cultural Relativism}

This essay has three purposes. The first one is to examine the relationships between ethnocentrism and relativism. Ethnocentrism is defined as a doctrine that takes three main forms: an imposed universalism, exoticism, and exacerbated, narcissistic particularism. Cultural relativism is seen as an attitude that proposes that moral concepts and values are incommensurable and should be viewed as valid only in the context of particular world's views. The second purpose is to show that ethnocentrism turns to be an unfounded and morally disastrous doctrine.The third purpose is to suggest that cultural relativism in its moderate version should be a moral guide for social anthropologists because it can teach them tolerance and skepticism to the standards of their own cultures.

KEYWORDS: ethnocentrism, relativism, incommensurability, cultures, world's view

Nicolás Sánchez Durá: Departamento de Metafísica y Teoría del Conocimiento,

Universidad de Valencia, España

nicolas.sanchez@uv.es

Desacatos, núm. 41, enero-abril 2013, pp. 29-48

Recepción: 18 de marzo de 2010 / Aceptación: 14 de agosto 2012 


\section{INTRODUCCIÓN}

S ea porque se estime que el mundo es efectivamente uno, homogéneo y continuo - como resultado de la insoslayable globalización-, sea por el desaliento que produce la dificultad de llegar a consensos transculturales sobre valores $y$ razones, muchos signos apuntan a un retorno renovado del etnocentrismo y a un desmayo del relativismo, antídoto de aquél. Parece que el propósito crítico del periodo clásico de la antropología hubiera concluido en una derrota o en el reconocimiento de un yerro respecto de la dirección hacia la que se orientó la parte más significativa de aquélla. Más allá de sus logros efectivos, la antropología social y cultural se desarrolló bajo el supuesto más o menos vago de relativizar lo propio a través de merodear por lo extraño. Otra cosa es que el etnocentrismo apareciera donde no se sospechaba, que ciertos puntos de partida metodológicos $-\mathrm{y}$ algunas conclusiones- implicaran inadvertidamente dosis variables

de etnocentrismo. Sin embargo, a pesar de las complicidades de la antropología en los procesos de colonización, creo que puede decirse que una parte significativa de su motivación fue, precisamente, un proceso constante de crítica interna, de impulso relativista, para desalojar las formas en las que el etnocentrismo mutaba. Pues bien, para merodear polémicamente en este retorno asustado de lo mismo frente al desafío de la alteridad cultural, hay que distinguir entre las variedades del etnocentrismo que se han configurado históricamente, a la vez que se piensa sobre la vigencia y el alcance del relativismo.

\section{EL ETNOCENTRISMO COMO INSTRUMENTO DE EXCLUSIÓN,TAMBIÉN COMO UNIVERSALIDAD IMPOSTADA}

Por acudir a los clásicos — es decir al Lévi-Strauss que escribe Raza e historia-, la forma más ruda del etnocentrismo, no por ello hoy desterrada por completo, es aquella que consiste en rechazar las formas culturales más distintas y distantes de las que nos son propias o familiares. Ese etnocentrismo es el que llama bárbaro o salvaje al extraño, el que, en el límite, niega su humanidad a los que participan de otras formas de vida y, excluyéndolos del ámbito cultural para recluirlos en el de la naturaleza, los considera como animales. Europa, Occidente o la tradición greco-romana y judeo-cristiana - como se quiera llamar a esa comunidad cultural de la que son partícipes los antropólogos, por más "nativos" que hoy puedan ser algunos de ellos- saben mucho de ese etnocentrismo. Sus efectos han sido devastadores debido al carácter expansivo de nuestras sociedades, donde "descubrir" se ha considerado sinónimo y equivalente de "conquistar". Como señala Lévi-Strauss, esa actitud etnocéntrica no es sólo nuestra: mientras los españoles - y también otros europeos- discutían sobre la humanidad en absoluto de los amerindios, algunos indígenas sumergían a los prisioneros blancos para observar si sus cadáveres se corrompían como el de cualquier vecino. Son multitud las sociedades ágrafas o tribales que se llamaban y se llaman a sí mismas "los hombres", "los buenos", "los completos", mientras que los que viven más allá de su medio se designan por términos que compendian un cúmulo de maldades.

Este tipo de etnocentrismo admite varios grados: desde excluir al otro absolutamente de la humanidad, hasta su consideración como humano pero defectivo, incompleto, truncado. Ese rango es, por ejemplo, el que se expresa en la distancia que media entre dos de los cuatro sentidos de bárbaro que distingue Bartolomé de Las Casas, por referirme a un caso bien conocido, que define entre bárbaros "en el sentido absoluto, estricto y propio" (Las Casas, 1988a: 99) y los que no lo son en sentido absoluto — simpliciter-, sino "secundum quid... según alguna parte o calidad que les falta para no ser bárbaros" (Las Casas, 1988b: 1577), es decir, los bárbaros por accidente. Las Casas cree que el primer tipo, los bárbaros simpliciter, corresponde a los esclavos por naturaleza de los que hablara Aristóteles en la Política, aquellos a los que se refería Homero en la 


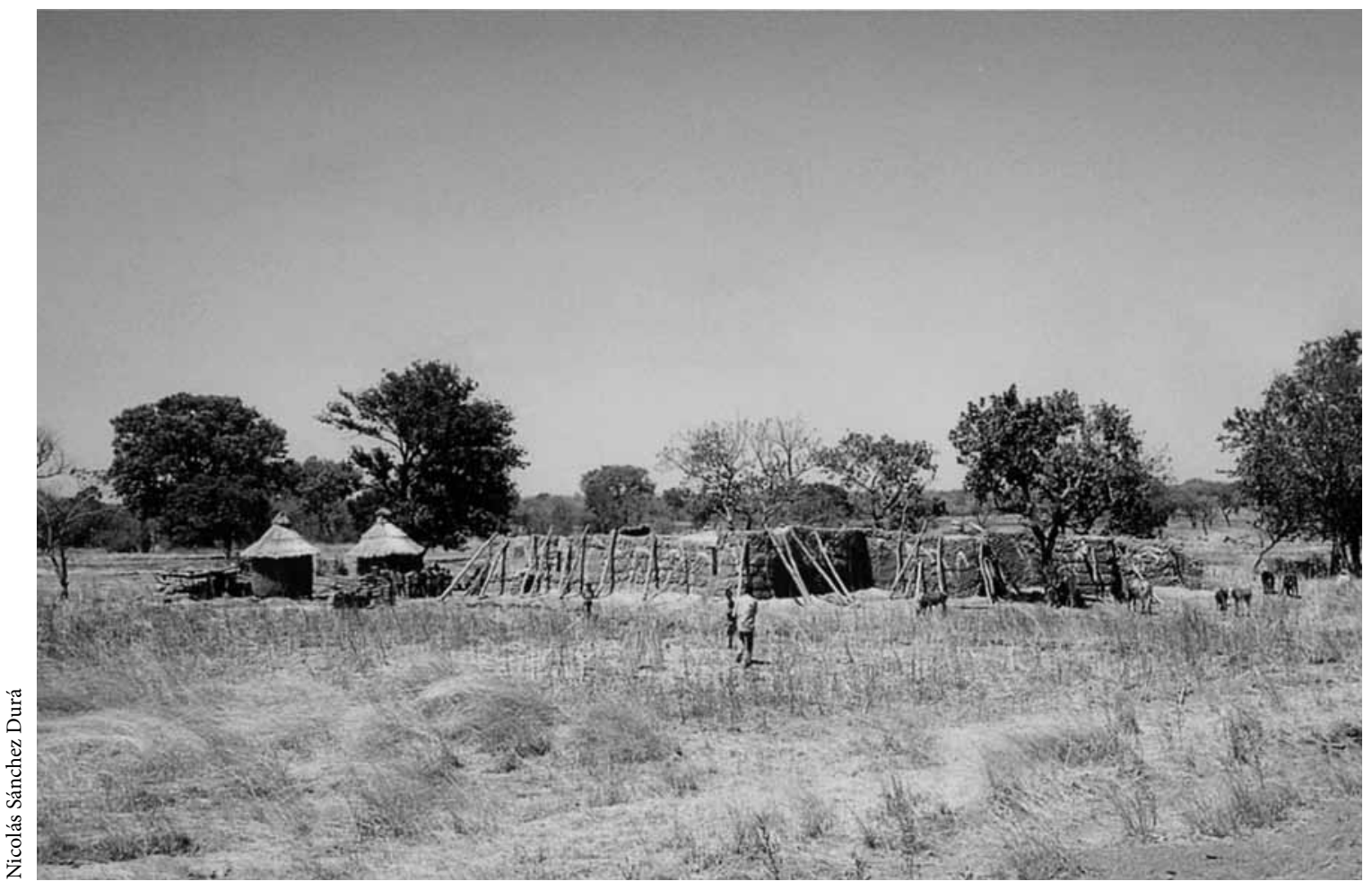

Casa racimo lobi, sur de Burkina Faso, cerca de Gaoua, 2003.

Ilíada como "sin tribu, sin ley, sin hogar". Su conducta moral y su capacidad racional son más cercanas a los animales que a los hombres. Según Las Casas, esta clase de barbarie no puede predicarse de "toda una raza, nación, región o provincia” (Las Casas, 1988a: 97), lo que equivaldría a considerar la naturaleza como defectiva y a su creador un chapucero y un malvado. Por tanto, de esta clase de bárbaros no puede sino haber ejemplos muy escasos. En última instancia, son razones teológicas las que le impiden a Las Casas aceptar tal clase de barbarie. Ahora bien, los bárbaros por accidente, secundum quid, no son irracionales, sino que son capaces de vivir políticamente según formas de vida civil que se basan en sus propias costumbres y leyes. No obstante, eso no les exime de ser bárbaros, porque también lo son para Las Casas:

todos aquellos que carecen de verdadera religión y fe cristiana, [...] todos los infieles, por muy sabios y prudentes filósofos que sean. La razón es porque no hay alguna nación (sacando la de los cristianos) que no tenga y padezca munchos y muy grandes defectos, y barbaricen en sus leyes, costumbres, vivienda y policías, las cuales no se enmiendan, ni apuran y reforman en su vivir a manera de regimiento, sino entrando en la Iglesia, recibiendo nuestra sancta y católica fe, porque sola ella es la ley sin mancilla que [...] limpia las heces de toda mala costumbre, desterrando la idolatría y ritos supersticiosos, de donde todas las otras suciedades, vicios e máculas privada y públicamente proceden (Las $\mathrm{Ca}$ sas, 1988b: 1583).

Ésa es la razón de que, citando a San Agustín en De Civitate Dei, afirme que:

donde no hay verdadera justicia, por mucha que sea, o parezca justicia, como es en los que carecen de cristiana fe, ni hay Derecho, ni justicia, y muy poco se puede llamar verdadera república. [...] los 
que carecen de la verdadera fe, no del todo hombres, sino bestias son y llamarse pueden (Las Casas, 1988b: 1584).

Éste no es el lugar para discutir la lectura que hace Las Casas de Aristóteles o pormenorizar su polémica con Ginés de Sepúlveda - he desarrollado este punto en Sánchez Durá, 1996-. Lo que me importa señalar es que la afirmación de que no puede haber una verdadera, plena y virtuosa comunidad política si no es una comunidad cristiana deja a los bárbaros secundum quid en una situación no por accidental menos precaria. Es decir: aun afirmando que "todo el linaje de los hombres es uno", y desde el criterio de quién participa y quién no de la verdadera religión, se dibuja una jerarquía donde no es posible ser verdaderamente hombre si no se participa de un modo de vida acorde con la religión verdadera. Más allá de las actividades políticas y polémicas de Las Casas en defensa de los indios, más allá de su convicción de que no cabe conquistarlos y después evangelizarlos, si se mantiene que sin la verdadera religión no hay justicia ni derecho ni verdadera vida política, si se afirma que las costumbres depravadas están en consonancia con la idolatría y, además, se retiene el principio de que las malas costumbres destruyen incluso una razón, en principio suficiente, hasta el punto de llevar a los depravados a ser casi irracionales y brutales - como asegura en otro lugar-, hay que concluir que la barbarie secundum quid no es cosa de gravedad menor cuando se trata de establecer una jerarquía de lo humano.

Me he detenido en Las Casas porque expresa un tipo de etnocentrismo que tiene como supuesto la igualdad del otro. Es decir, al extraño se le reconoce su humanidad y la igualdad de derechos, pero a costa de hacerlo uno de nosotros, pues en sí mismo el otro es inadmisible. Encontramos este punto de vista, aunque formulado en términos ilustrados y laicos, en Condorcet. Para él todos los hombres tienen los mismos derechos, también el de ser civilizado. Por tanto, los más civilizados - franceses e ingleses - tienen el derecho y el deber de extender la civilización incluso por la fuerza: "las poblaciones europeas deben civilizar o hacer desaparecer a las naciones salvajes", afirmó en su Bosquejo de un cuadro histórico de los progresos del espíritu humano (Condorcet, 1980).

Podemos encontrar una forma más elaborada de este punto de vista en La razón en la historia, de Hegel, que opina que la desaparición de los pueblos amerindios se debe a la inferioridad de su fuerza física, incluso de su estatura y de su cultura. Fueron pueblos casi carentes de inteligencia, de ahí su resistencia absoluta a la educación. Por eso las organizaciones eclesiásticas los trataron como partícipes del "estado natural de incultura y barbarie" y se impusieron a ellos con autoridad espiritual y con trabajos para despertar y satisfacer sus necesidades. Dado que vivían como niños, privados de toda reflexión, "asumieron, respecto de ellos, la posición de los padres frente a sus hijos" (Hegel, 1965: 234). Por todo ello, concluye en una neta justificación de nuestro derecho a esclavizar a los otros. Dice en relación con "los negros", como los llama de manera indistinta, dada su identificación inmediata con la naturaleza:

su conciencia no ha alcanzado la contemplación de una objetividad sólida, como por ejemplo Dios, la ley, a la cual pueda adherir la voluntad del hombre, y por la cual pueda llegar a la intuición de su propia esencia (Hegel, 1965: 250-251).

El negro es el hombre inconsciente de sí y no podemos encontrar nada en él que concuerde con lo humano. Para Hegel - de nuevo lo mismo dicho de otra manera-puede hablarse sólo impropiamente de "religión de los negros", pues ésta no va más allá de sus dos momentos: la magia y el fetichismo. Estrictamente, no cabe hablar de verdadera religión, porque ésta comienza cuando el hombre "reconoce un ser supremo, que es en sí y para sí, totalmente objetivo, absoluta esencia determinante, poder superior por relación al cual el hombre es algo más débil y más bajo" (Hegel, 1965: 252-253). Tanto es 
así que para Hegel no puede encontrarse mayor desprecio por el hombre mismo que entre los negros que viven en estado de naturaleza. Este desprecio ético y jurídico es lo que constituye su principal característica y, por tanto, su gobierno es siempre tiránico. Entre los negros mismos reina la esclavitud y ésta es la relación sobre la que se basa su derecho.

Tanto Las Casas como Hegel apelan a una integración de los que pertenecen a otras sociedades a la historia universal: historia de la salvación en el caso de Las Casas, historia secular en el caso de Hegel. Si bien - y en esta falacia radica su etnocentrismo- la universalidad no es sino una proyección de la propia particularidad: nuestra religión, nuestras formas políticas, etc. Dos maneras de decir lo mismo: los otros deben renunciar a ser como son si quieren ser verdaderamente libres y moralmente responsables, es decir, sujetos de pleno derecho. Véase cómo este etnocentrismo, que he llamado igualitario, ha sido la base del colonialismo y de su todavía hoy mal conocida cosecha no de civilización e igualdad, sino de explotación y dolor. Frente a este etnocentrismo reacciona, valga el ejemplo, el poeta martinicano Aimé Césaire, una de las figuras centrales del movimiento de la negritud. En su Discurso sobre el colonialismo de 1950 afirmó que al "muy distinguido, muy humanista, muy cristiano burgués del siglo $\mathrm{xx}$ " hay que decirle que lleva un Hitler dentro, aunque lo ignore:

si lo vitupera, es por falta de lógica, y en el fondo lo que no le perdona a Hitler no es el crimen en sí, el crimen contra el hombre, no es la humillación del hombre en sí, sino el crimen contra el hombre blanco, es la humillación del hombre blanco, y haber aplicado en Europa procedimientos colonialistas que hasta ahora sólo concernían a los árabes de Argelia, a los coolies de la India y a los negros de África (Césaire, 2006: 15).

Si tales palabras parecen exageradas, considérese el caso del Estado Libre del Congo de Leopoldo II de Bélgica y téngase en cuenta que fue la propia teoría nacional-socialista la que afirmó que Alemania debía buscar en Europa el "espacio vital" que Europa había encontrado en las colonias so capa de civilizarlas (Traverso, 2003: 57 y ss.). Hoy las formas más rudas de este tipo de etnocentrismo nos causan, por lo general, un gran rechazo no sólo moral, sino estético. Entre otras razones, por las que Césaire esgrimió: porque al tratar a algunos hombres como objetos, acaba tratándolos a todos como objetos; porque al ver al otro como menos que humano, acaba convirtiéndonos en sujetos carentes de humanidad. Sin embargo, el etnocentrismo inherente a una concepción evolucionista de la historia, bajo los ropajes del "progreso" o de la "modernización", todavía inspira muchas políticas tutelares que esconden afanes de hegemonía política. Políticas éstas que no tienen necesariamente que provenir de injerencias estatales exteriores, pues pueden ejercerse desde ciertos estamentos o clases de un Estado sobre sectores de las propias poblaciones que se consideran "arcaicas", "retardatarias", "premodernas", etcétera.

\section{EL ETNOCENTRISMO COMO EXOTISMO: LOS OTROS COMO FANTASMAS DEL DESEO}

Hay otro tipo de etnocentrismo que no trata al otro como un hombre defectivo que será pleno una vez tutelado. Es un etnocentrismo - prima facie enmascarado de relativismo - cuya característica es considerar al extraño como objeto de su fantasía. Un aspecto, por cierto, también implícito en Las Casas, cuando en sus descripciones caritativas de los amerindios los concibe como cristianos ideales en potencia, más proclives a cumplir auténticamente el Evangelio. En esas descripciones los indios resultan adornados con las cualidades que él desearía que adornaran a los europeos, pero de las que, constata, éstos carecen. Ese mecanismo de proyección en el otro de los valores que se quiere defender, convirtiéndolo en el espejo idealizado para mirarse uno 
mismo y mirar a sus semejantes, ha tenido muchas versiones y en todas al extraño, así desfigurado, se le constituye en instancia crítica desde donde avistar, como contrapunto, lo que se desea que se cumpla entre los propios. Es el caso de Montaigne y los supuestos caníbales usados en su diatriba contra el fanatismo religioso en los tiempos de las guerras entre católicos y hugonotes, o el de Gauguin cuando convierte a los tahitianos en el espejo donde debe mirarse críticamente la moral sexual burguesa de finales del siglo xIx. Este tipo de etnocentrismo adopta el punto de vista opuesto al que veía al otro como inhumano o como hombre incompleto.

Sin embargo, tampoco las peculiaridades de los extraños son reconocidas en este caso, porque en estas descripciones el otro aparece como desprovisto de todo lo que nos caracteriza, de manera que resulta una inversión en negativo de lo que constituye la civilización que pretende criticarse. Este etnocentrismo es, paradójicamente, doble. Por una parte, el sujeto de la enunciación se sitúa exclusivamente desde el punto de vista que supuestamente encarnan los otros. Se adopta lo que Todorov llama un "globalismo axiológico": no sólo cada rasgo particular conserva el mismo valor y sentido en todos los contextos, sino que el juicio de valor se extiende a toda la sociedad, o todo es bueno o todo es malo. A la vez, los otros son la encarnación de unos valores culturales que pertenecen a una tradición que les es ajena, que los desfigura. Tal tipo de etnocentrismo puede tener usos menos "nobles" que los de Montaigne o Gauguin, pues el ajeno, aunque descrito con simpatía, puede ser construido como objeto de la fantasía con el único fin de satisfacer los fantasmas y obsesiones - a menudo de corte libidinosode los receptores de tales descripciones. El novelista francés Pierre Loti puede ser un ejemplo de esa literatura exótica, pero también buena parte de la

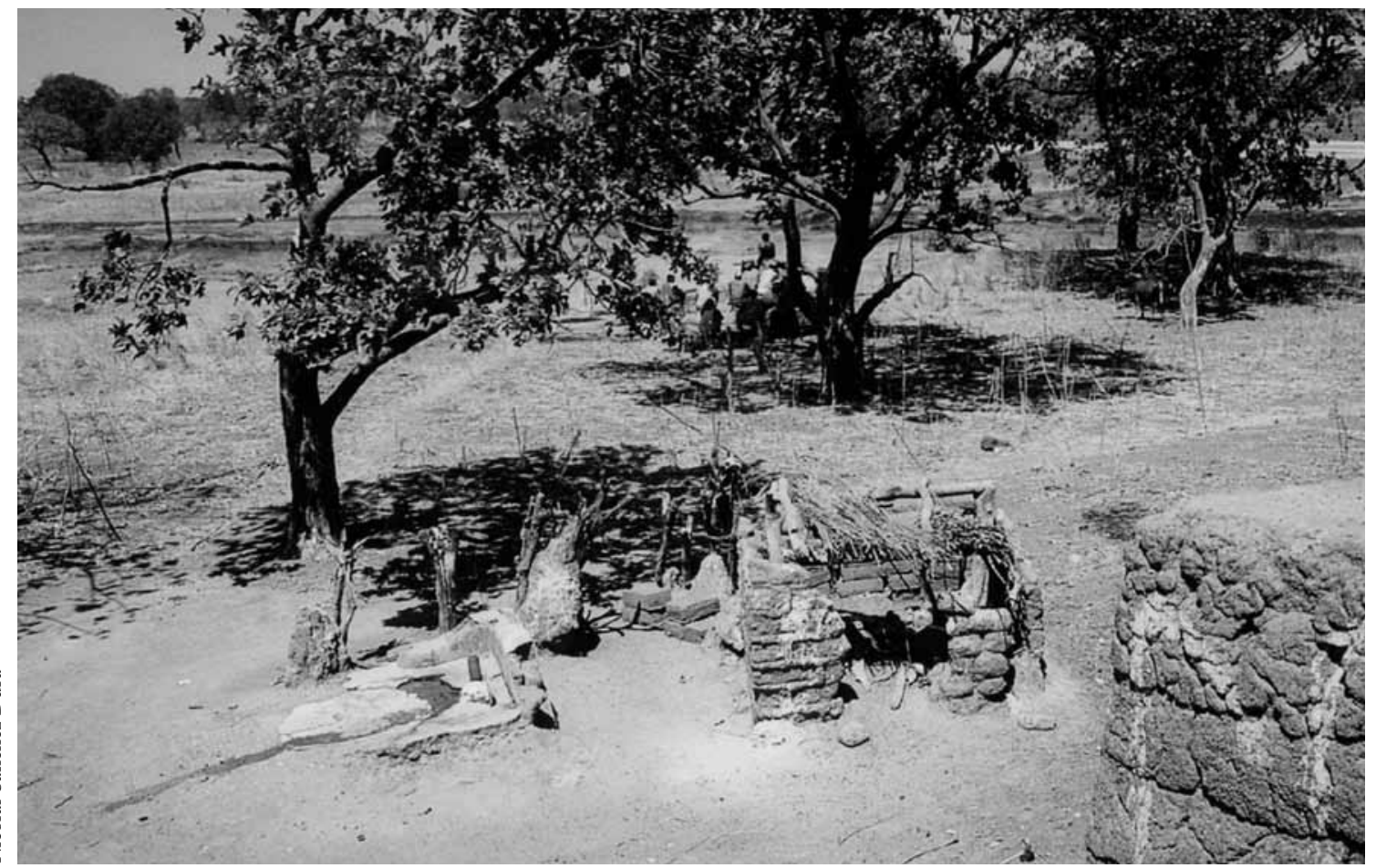

La misma casa: al fondo la familia realiza el oráculo de las gallinas en ocasión del fallecimiento de uno de los miembros para saber si su muerte es cosa de brujería, 2003. 
pintura de Gauguin y de sus escritos tahitianos (Sánchez Durá, 1997 y 1998). Este etnocentrismo "de buenas intenciones" está mucho más extendido de lo que parece. Como dice un proverbio castellano: "de buenas intenciones está empedrado el camino al infierno". De hecho, parte de la mal llamada "antropología posmoderna" se ha dedicado a la crítica de todas las representaciones exotistas o de las diferentes versiones del "buen salvaje" y de la Arcadia Feliz.

\section{EL ETNOCENTRISMO COMO PARTICULARISMO NARCISISTA EXACERBADO}

Ahora bien, la huida de un falaz universalismo puede concluir en un particularismo exacerbado de paradójicas consecuencias etnocéntricas. Éste es otro etnocentrismo que corresponde al periodo que media entre la época en la que existían poblaciones o etnias separadas y estancas - a las que accedía el antropólogo a través de toda clase de dificultades físicas sirviéndose de intermediarios- y aquella en que la variedad cultural está presente no lejos, sino entre nosotros, en las antiguas metrópolis coloniales y también en las antiguas colonias. Una figura de ese particularismo que desemboca en un nuevo etnocentrismo es el Lévi-Strauss de Raza e historia y sus conclusiones, 20 años después, en Raza y cultura. En el primer texto había concluido con una paradoja: lo que hace fecundo el encuentro de culturas es su diferencia, aunque en el curso de los intercambios y préstamos culturales llega el momento en que ya no hay nada que intercambiar. Si se parte del valor intrínseco de las diferencias culturales, hay que pagar el precio de la relativa separación y distancia entre culturas, y mantener cada una rígidamente adherida a sus valores. Más tarde Lévi-Strauss afirma que no sólo hay que permanecer sordo a otros valores, sino que puede llegarse "hasta el rechazo y aun a su negación”. La posición del antropólogo francés es todo menos convenenciera: soñamos con "la igualdad" y "la fraternidad" entre los hombres —nótense los dos valores republicanos e ilustrados mencionados-, pero ese sueño compromete la diversidad. Es decir:

la lucha contra todas las formas de discriminación participa de ese mismo movimiento que arrastra a la humanidad hacia una civilización mundial, destructora de esos viejos particularismos en los cuales recae el honor de haber creado los valores estéticos y espirituales que dan su recompensa a la vida... si la humanidad no se resigna a [sólo ser capaz]... de dar a luz obras bastardas, invenciones groseras y pueriles, deberá aceptar que toda creación verdadera implica una cierta sordera a la llamada de otros valores, pudiendo llegar hasta el rechazo y aun a su negación. Porque no se puede, a la vez, fundirse en el goce del otro, identificarse con él y mantenerse diferente. Plenamente lograda, la comunicación integral con el otro condena en un plazo más o menos breve la originalidad de su creación y la mía (LéviStrauss, 1993: 140-141).

Lévi-Strauss no ve nada insano en esa actitud: el etnocentrismo empieza cuando se jerarquizan las culturas, y él no lo hace, aunque siempre habrá comunidades que sientan más afinidad por unas que por otras sobre la base de la cercanía en el género de vida. De otra manera, lo mismo vale para el antropólogo: aunque busque no la cercanía, sino el mayor contraste posible, ello no impide que se sienta mejor entre unos que entre otros. En este contexto ocurrió la discusión entre el antropólogo francés, Clifford Geertz y Richard Rorty. Lévi-Strauss y Rorty, desde un diagnóstico diferente de nuestro tiempo, llegan a una conclusión similar. Para el primero, alcanzar un consenso transcultural sobre lo bueno, lo bello y lo razonable compromete la diversidad, un valor superior en tanto condición de posibilidad de la creación. Para Rorty, buscar ese consenso es un sueño que debe abandonarse porque tal convergencia está lejos de producirse ahora y en el futuro. Ambos abogan por una especie de narcisismo cultural centrado en el horizonte propio, eso sí, cada comunidad celosa del suyo. 


\section{DESDE EL OTRO LADO DE LA TRINCHERA: DIFICULTADES ACTUALES PARA FORMULAR EL RELATIVISMO}

Uno de los problemas es cómo debe entenderse hoy la identidad cultural, tanto en lo que se refiere a la mismidad - consistencia y estabilidad de lo que define una cultura a lo largo del tiempo- como a la ipseidad - la coherencia de lo que distingue a una cultura de otra-, porque uno de los supuestos compartidos por el etnocentrismo y su opuesto, el relativismo cultural, es una concepción rígida de la identidad cultural. Esto puede percibirse mejor si tratamos la cuestión desde la pluralidad de contextos de relativización a los que el relativismo apela para defender las particularidades, no desde lo que el etnocentrista defiende. En efecto, cuando se habla de relativismo en general hay que tener en cuenta tres factores: 1) qué es aquello que se relativiza -la ontología, las razones, la verdad, los valores-; 2) respecto de qué marco o contexto se hace relativo lo relativizado - las teorías, los lenguajes, los esquemas conceptuales, las culturas-, y 3) la fuerza o radicalidad con la que se relativiza algo respecto de un marco o contexto de referencia. Los puntos 1 y 2 permiten elaborar dos clasificaciones distintas de relativismos. ${ }^{1}$

Si fuera imposible determinar los marcos de relativización - la culturas, en nuestro caso-, la polémica etnocentrismo versus relativismo adquiriría una tonalidad diferente a la que ha tenido hasta ayer. Malamente podría formularse la tesis del relativismo cultural - que los valores, razones, etc., son relativos a una cultura- si no hay manera de

\footnotetext{
${ }^{1}$ En cuanto a lo que se relativiza hablaremos de diversos objetos de la relativización: valores morales, como lo bueno y lo malo; valores estéticos, como lo bello y lo feo; valores epistemológicos, como lo verdadero y lo falso, etc. En cuanto al marco de relativización acuñaremos tipos de relativismo: relativismo epistemológico si nuestro marco de referencia es el sistema epistemológico, relativismo lingüístico si el marco de referencia es el lenguaje, relativismo cultural si el marco de relativización es la cultura. Este último tipo es el que nos interesa elucidar en el presente ensayo.
}

identificar una cultura respecto de otras, si hablar de culturas es confundir la unicidad de objeto que los antropólogos necesitan para fraguar su discurso disciplinar - en la pluralidad de sentidos de disciplinar - con la pluralidad irreductible de lo existente, $o$ si resulta que, dada la mundialización de una sola cultura triunfante, afirmar el relativismo cultural no es más que obstinarse en suponer algo - la diversidad de culturas - desaparecido de facto de la faz de la tierra. De estas tres afirmaciones, ofrecen mayor interés dos de ellas: la que habla de la dificultad de establecer criterios de identificación cultural y la que defiende que el concepto de cultura implica el supuesto de una unicidad deseada pero nunca dada ready made. En cierto sentido ambas convergen. $\mathrm{Mi}$ punto de vista es que si bien debe atenderse lo que ambas subrayan, no por ello deja de ser posible formular la tesis del relativismo cultural frente al renovado etnocentrismo.

James Clifford, defensor del análisis retórico de las monografías etnográficas en cuanto textos de un determinado género, ha argumentado que éstas son ficciones en el sentido de que "inventan cosas no efectivamente reales" - "things not actually real" (Clifford, 1986: 6) -. Entre ellas, las buenas son "ficciones verdaderas", pero en todo caso determinadas contextual y retóricamente por su género literario, por determinaciones políticas y por tanto históricamente, pues todas esas determinaciones son cambiantes. Así, tales determinaciones tienen como efecto que esas ficciones estén basadas en exclusiones sistemáticas: las culturas, como los retratos, son simplificaciones que dependen de elecciones de foco y de los avatares de las relaciones de poder en sentido amplio. Entonces es improcedente hablar de "los dinka", "los nuer" o "los trobriandeses" como tipos culturales o como miembros indistintos de la cultura dinka o la cultura nuer: “cultura' es siempre relacional, una inscripción de procesos comunicativos que existen, históricamente, entre sujetos en relaciones de poder" (Clifford, 1986: 15). Tal polifonía en los "modos de producción textual" quiebra la legitimidad epistemológica y moral de una supuesta 
autoridad etnográfica monocorde que tratase de representar las culturas como objetos científicos susceptibles de descripciones acabadas, no sólo porque no estén ya a la mano para ser descritos, sino porque las culturas tampoco son "un corpus unificado de símbolos y significados que puedan ser definitivamente interpretados" (Clifford, 1986: 19). Si leyéramos, por ejemplo, "los dinka interpretan a menudo los accidentes o las coincidencias como actos de la divinidad que sirven para distinguir la verdad de la falsedad a través de signos aparentes a los hombres", deberíamos preguntarnos si para las mujeres dinka también vale el aserto, pues bajo el genérico hombre lo que a menudo se esconde es el específico varón. Llegados a este punto, la opción que denuncia el uso del concepto cultura como una disciplinarización - tanto en el sentido de constituir una disciplina con pretensiones científicas como en el de acallar la pluralidad de voces que cuestionan las descripciones unitarias e integradas de las supuestas culturas - converge con aquella otra que afirma la dificultad de establecer un criterio de identificación cultural que posibilite establecer los límites de una cultura, pues toda cultura, en la opción que comentamos, parece disgregarse en una fragmentación inacabable.

Es significativo que fuera Renato Rosaldo en quien Paul Feyerabend se apoyara en su último artículo, escrito antes de fallecer en Zurich en 1994. Allí asegura que "el objetivismo y el relativismo son quimeras" (Feyerabend, 1996: 39), mantiene un punto de vista moral y político universalista que defiende las intervenciones, incluso "drásticas", en todas las poblaciones donde haya problemas médicos, de nutrición, ambientales, de derechos humanos o con la vida de las mujeres. Feyerabend asevera que tales intervenciones "se deben realizar después de un prolongado contacto no sólo con los 'líderes', sino con la población de que se trate". Insiste en el cierre de su artículo en que hay que juzgar e intervenir "con la debida atención a las opiniones de la población local" (Feyerabend, 1996: 41-42). Es un caso de legitimación de la tutela al que nos referíamos antes.
Ahora bien, desde el punto de vista del asunto que tratamos es interesante señalar que tal posición moral y política tiene como premisa pensar que "potencialmente, cada cultura es todas las culturas", pues las diferencias culturales no son más que "manifestaciones concretas y variables de la naturaleza humana”. No tiene sentido hablar de ámbitos culturales cerrados y de significados precisos. La interacción entre "las culturas, los ámbitos lingüísticos y los grupos profesionales" es constante, por ello "es absurdo hablar de objetividad o de sentido relativo dentro de unos límites nítidamente definidos". Feyerabend se apoya en Rosaldo de dos maneras que ejemplifican dos de las opciones que he indicado: la que propone que hablar de culturas es fingir la unicidad de un objeto necesario para fraguar la disciplina antropológica, y otra que en razón de la mundialización de una sola cultura cree periclitada su pluralidad. Este aspecto es el invocado por Feyerabend en la siguiente cita de Rosaldo: "En el mundo actual postcolonial, la noción de una cultura auténtica como un universo autónomo e internamente coherente ya no es sostenible, excepto quizá como una 'ficción útil', o una distorsión reveladora' (Rosaldo, 1991: 198). Por otra parte, retoma de nuevo a Rosaldo y alude también a una concepción de las culturas que otra vez acaba disolviéndolas en un sumatorio de individualidades cuya espontaneidad de recursos es irreductible a cualquier pertenencia cultural unitaria. Así, la antropología objetivista, que postula "sistemas cerrados", que pretende descubrir unas reglas estrictas que guían la conducta como un ídolo, se considera un obstáculo para aquilatar cuántas cosas acaecen en la vida de manera imprevista e inesperada. De ahí su alusión a Gloria Anzaldúa - la lesbiana chicana de la que habla Rosaldo- como muestra ejemplar de lo que defiende, porque Gloria Anzaldúa es alguien que aprende a "hacer malabares con la cultura" (Rosaldo, 1991: 197), a ser indio en la cultura mexicana y a ser mexicano desde el punto de vista anglosajón. Son los casos que tocan límites los que revelan la pluralidad insospechada de recursos culturales. Por eso Gloria 


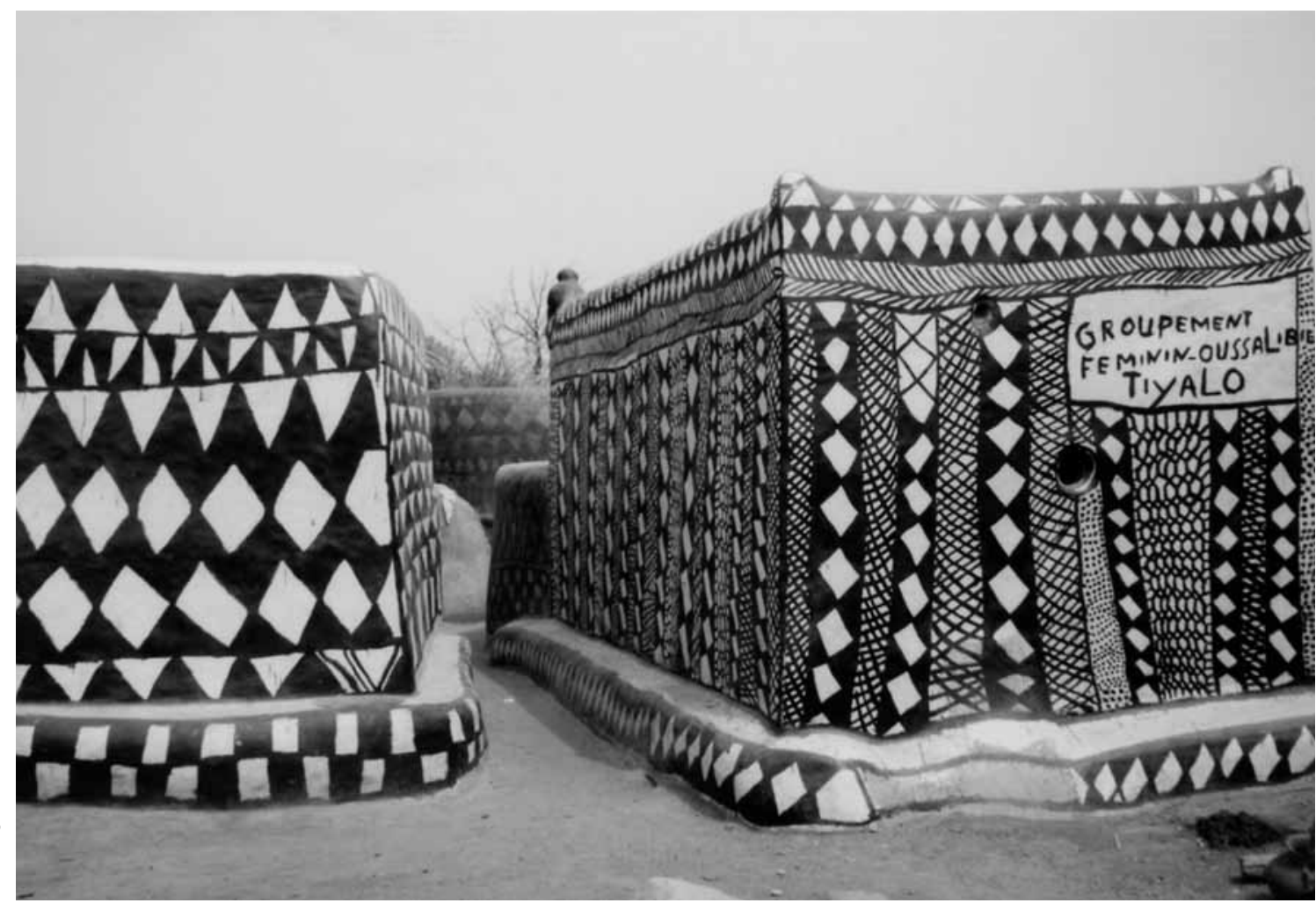

Reino de Tiebelé, sur de Burkina Faso, muy cerca de la frontera con Ghana: casa gurunsi que alberga a la “agrupación femenina”, 2001.

Anzaldúa tiene una personalidad plural, contradictoria y ambivalente.

En la reflexión epistemológica sobre la Historia también se han producido afirmaciones afines. Como muestra véase la discusión suscitada por el libro de Robert Darnton, The Great Cat Massacre and Other Episodes in French Cultural History (1984). Darnton se dedica a interpretar uno de los capítulos de las memorias del aprendiz de impresor Nicolas Contat -Anecdotes typographiques: où l'on voit la description des coutumes, mours et usages singuliers des compagnons imprimeurs [1762] (1980) - para discernir la "visión del mundo" de los franceses en el periodo inmediatamente anterior a la Revolución francesa. La razón para elegir este texto - que cuenta una gran matanza de gatos en la imprenta del maestro Jacques Vincent llevada a cabo por sus aprendices y oficiales- reside en su sentido prima facie opaco. Darnton aboga por una "explicación etnológica" de los textos porque "cuando te das cuenta de que no estás captando algo — una broma, un proverbio, una ceremonia - particularmente significativo para los nativos, aprecias dónde captar un sistema significativo extraño con el fin de desentrañarlo. Si captamos la broma de la gran masacre de gatos, es posible captar un ingrediente básico de la cultura artesanal bajo el Antiguo Régimen" (Darnton, 1987: 78).

El historiador francés Roger Chartier critica a Darnton no sólo por su concepto hermenéutico de cultura importado de Geertz, sino por la posibilidad de hablar de "culturas" en absoluto. Le parece inadecuado afirmar que en un determinado momento y en un lugar dado "una cultura particular [...] esté organizada de acuerdo con un repertorio de elementos simbólicos", al igual que postular que "las 
formas simbólicas estén organizadas en 'sistemas"'. Ello supone tal coherencia e interdependencia entre los símbolos que sería necesario considerar la existencia de "un universo simbólico unificado y compartido". Precisamente eso es lo que le parece improcedente suponer durante el Ancien Régime dadas las múltiples divisiones y fracturas de edad, género, estatus, profesión, religión, residencia, educación, etc.: “'Tenemos pues el derecho de pensar que, más allá de esta discontinuidad de culturas particulares [...], existía una cultura simbólica de la que pudiera decirse que englobara a las otras y proponer un sistema de símbolos aceptado por todas?". Chartier concluye la invalidez de "un idioma general' capaz de dar cuenta de todas las expresiones singulares" (Chartier, 1985: 690).

Aunque no lo pretenda, Chartier parece invalidar el concepto de cultura en absoluto, pues los mismos argumentos que utiliza para cuestionar que "una cultura particular [...] esté organizada de acuerdo con un repertorio de elementos simbólicos" pueden utilizarse para cuestionar "las particulares culturas discontinuas" en las que se fracciona la unidad que Darnton supone. Siempre se podría recurrir al criterio de las diferencias individuales en los ámbitos de la edad, la religión, la residencia, etc., para concluir la no posibilidad de considerar agrupación cultural alguna. Como en el caso de Clifford, parece que toda cultura acaba disgregándose en una fragmentación inacabable. Creo que hay una incoherencia en la argumentación de todos los autores reseñados. Chartier, en su crítica, recurre al uso del concepto de cultura de una manera que no quedaría a salvo de sus propias críticas a Darnton. De hecho, Chartier está al tanto de la relevancia del problema, como se constata en su afirmación:

el asunto hoy más urgente en el ámbito de la historia cultural [...] es el de las diferentes maneras en que los grupos o individuos hacen uso, interpretan, y se apropian de los motivos intelectuales o de las formas culturales que comparten con otros (Chartier, 1985: 688).
En cuanto a Clifford, tampoco se podría hablar de lo que piensan "las mujeres dinka", ya que siempre cabría hacer especificaciones de edad, estatus, etc. Por otra parte, parece difícil hablar de la "cultura de las mujeres dinka" sin involucrar a agrupaciones más extensas, como la "cultura dinka" e incluso la "cultura ágrafa", etc. En general, puede decirse que todos necesitan, pragmáticamente, suponer agrupaciones, unidades culturales, tipos culturales, o cualquier otra expresión que sirva para designar determinaciones culturales comunitarias. Es más, parece imposible describir la identidad de los individuos si no es apelando a sus diversas pertenencias culturales. En el caso de Gloria Anzaldúa, traído por Feyerabend, su personalidad se describe como "plural" y "contradictoria", lo cual supone identidades culturales - las culturas india, mexicana, chicana, anglosajona, lesbiana...- de las que Feyerabend quisiera prescindir.

\section{A VUELTAS CON LA IDENTIDAD CULTURALY LA POSIBILIDAD DEL RELATIVISMO COMO ANTÍDOTO DEL ETNOCENTRISMO}

No es mi intención defender un concepto "fixista" de cultura. Negar la hibridación de formas culturales atenta contra la evidencia más palmaria. Por tanto, son oportunas las consideraciones de Chartier - y en cierto sentido también de Clifford- respecto del peligro metodológico que supone considerar de forma excesivamente extensiva aquello que denominamos "una cultura". Como ha defendido Geertz, las culturas ya no pueden ser concebidas como unidades de consenso sobre lo bueno, lo bello y lo verdadero. Para decirlo con sus imágenes: no podemos seguir pensando el mundo según la metáfora de un paisaje puntillista donde cada mota es una cultura considerada como una unidad compacta, homogénea, simple y uniforme (Geertz, 2002: 253-254). No obstante, el rechazo a entender la cultura como un "cuenco" de bordes firmes e inalterables que modela de forma idéntica todo lo que 
contiene no puede comportar la renuncia a articular un concepto de cultura operativo en la investigación empírica que permita hablar de la "cultura catalana" y de la "cultura española".

Desde este punto de vista, debe subrayarse que las concepciones aludidas parecen compartir, de manera inadvertida, una misma concepción del uso de los conceptos. Diríase que rechazan el uso del término cultura porque consideran que necesariamente comporta una aplicación demasiado rígida. Ahora bien, tanto cultura, como obra de arte o amistad son nociones de límites borrosos en su aplicación, ni más ni menos como casi todos los términos de una lengua. ${ }^{2}$ Es decir, los límites de la aplicación de las expresiones verbales no están rígidamente determinados para todos los casos. Aun teniendo en cuenta que la ambigüedad es insoslayable, ello no impide que no puedan darse explicaciones de sentido de los términos siempre mejorables: describiendo sus usos y contrastando el que queramos explicar con otros que le sean próxi-

Por tanto, no puede rechazarse el uso de conceptos como la "cultura de las mujeres dinka", la "cultura dinka" o la "cultura del Antiguo Régimen en Francia" porque sea problemático encontrar condiciones necesarias y suficientes - del tipo "un individuo es miembro de la cultura $x$ y no de la cultura $y$ si, y sólo si..."- que establezcan unívocamente la pertenencia a un "cuenco" cultural sobre la base de una característica general que se predicara de todos sus miembros. En general, cuanta más extensión le demos al concepto "la cultura $x$ " - la cultura

\footnotetext{
${ }^{2}$ Podrían excluirse los términos monocriteriales. Esos términos que aparecen en juicios claramente analíticos - como "todos los solteros son no casados" - tienen la característica especial de que hay una ley sin excepciones asociada, por ejemplo a "soltero", de la forma "alguien es soltero si y sólo si nunca ha estado casado". Además, esa ley tiene dos notas: a) los hablantes de una lengua no asocian ningún otro "si y sólo si" sin excepciones con dicho nombre, y b) ese enunciado de la forma "si y sólo si" sin excepciones es un criterio, de forma que los hablantes pueden decir si alguien es o no un soltero viendo si está casado (Putnam, 1983).
}

francesa bajo el Antiguo Régimen - más abstractas serán sus notas y por ende menos útil para captar la multiplicidad de diferencias como hoy se presenta, que es de lo que se trata. Sin embargo, "eso de lo que se trata" no puede tomarse sin ulterior precisión. "De lo que se trata" puede implicar una gran diversidad en función de consideraciones pragmáticas acerca del contexto, de los fines, de las motivaciones y los intereses que auspicien las investigaciones. En ocasiones, miradas generales perderán necesariamente finura discriminatoria; en otras, la capacidad de filigrana supondrá la pérdida de panorámica. Pero siempre se puede utilizar la comparación y el contraste para dilucidar el sentido en el que se usa la "cultura $x$ " como distinta de la "cultura $y$ ", o qué queremos decir cuando afirmamos que "Ogotemméli, el informante de Griaule, era un dogón” - un dogón de la época en que Griaule los visitó-. Me serviré aquí de una reflexión de Geertz, a riesgo de traicionarlo, sobre las cuatro décadas de su experiencia de campo (Geertz, 1996a: 51-70).

Geertz describe que el aprendizaje del javanés y del árabe le llevó a captar que los javaneses enfatizaban el estatus de los individuos, mientras que los marroquíes subrayaban el género. El javanés era escaso en inflexiones para marcar el género, pero gramaticalmente meticuloso para las diferencias jerárquicas. El árabe marroquí tenía inflexiones de género para casi todos los aspectos de un predicado, pero tal proliferación de recursos no existía en el caso de los marcadores de estatus. Dado que ni javaneses ni marroquíes son insensibles ni indiferentes, respectivamente, a las diferencias sexuales ni a las de posición y reputación, Geertz concluyó "que en un lugar la diferencia sexual se expresa y se comprende como una variedad doméstica del estatus y que en el otro las desigualdades de prestigio se asimilan al imaginario idiosincrático del sexo". Lo interesante del ejemplo es lo que él mismo subrayó: que la captación de las diferencias entre esas dos culturas surge de la conjunción que el antropólogo establece entre dos aspectos de dos lenguas habladas por dos comunidades, y no de los hablantes de 
esas lenguas. En este caso sus profesores de árabe marroquí y javanés, al insistir sólo en los usos gramaticales correctos correspondientes, dejaban invisibles sus centros de interés, en definitiva, sus creencias.

Ahora bien, algunos detalles nos indican en qué tipo de creencias debemos fijarnos a la hora de identificar culturas - sin olvidar tanto los límites borrosos de las mismas como las necesarias consideraciones pragmáticas en el momento de identificarlas-. Geertz relata que empezó a percibir las diferencias entre el javanés y el árabe marroquí cuando reparó en el comportamiento de sus instructores: el nerviosismo de los javaneses era notable cuando sus errores de aprendizaje versaban sobre la marcación del estatus, mientras que ignoraban o dejaban pasar sin igual severidad los errores de género. Por su parte, los instructores marroquíes no perdonaban los errores en las expresiones de género y se mostraban benevolentes con los de estatus.

Puede ser clarificador preguntar si para nosotros y para un javanés el carácter del enunciado "la diferencia sexual se expresa y se comprende entre los javaneses como una variedad doméstica del estatus" es el mismo. Para nosotros es un enunciado empírico, fruto de una investigación, cuyo contenido proposicional es una creencia acerca de un aspecto del mundo - cómo es la vida social de los javaneses-. No obstante, nosotros podríamos decir que para los javaneses no es un enunciado empírico a pesar de su apariencia. En primer lugar, es un enunciado que no es proferido espontáneamente por los javaneses, sino que pertenece a la etnología, a la teoría antropológica. En segundo lugar, el uso de ese enunciado no es el mismo para el etnógrafo o sus lectores - y aun entre éstos hay diferencias-y para los javaneses: para los primeros pertenece al ámbito de la certeza — de grado variable - intelectual, mientras que para los segundos pertenece al ámbito de la acción - lo que se muestra como síntoma en la conducta de los instructores de javanés ante los diferentes errores del aprendiz Geertz-. Lo que describe ese enunciado - descripción hecha por el antropólogoson certezas indubitables supuestas en la conducta lingüística, así como en la acción social de los javaneses. Se trata de una certeza previa tanto a los diferentes enunciados concretos que los javaneses puedan hacer como a sus acciones particulares en los contextos de su vida.

Recurriendo al Wittgenstein de Sobre la certeza, he relacionado el enunciado sobre la diferencia sexual y el estatus entre los javaneses con lo que Wittgenstein llamaba "proposiciones pseudoempíricas". Wittgenstein afirmó que del fundamento del pensamiento y del lenguaje forman parte no sólo las proposiciones de la lógica, sino "también algunas proposiciones que tienen la forma de las proposiciones empíricas". No puede decirse que los sujetos conozcan propiamente tales pseudoproposiciones, ya que para ellos no hay nada que pueda ser más evidente e indubitable - $\mathrm{y}$ así poder servir como razón o evidencia justificativa- que lo que éstas afirman. Paradójicamente, no por no poder decir que propiamente se las conoce se les puede poner en tela de juicio, ya que esas peculiares proposiciones constituyen el término de las justificaciones disponibles en una comunidad lingüística, lo que no supone que ese término se resuelva en una especie de visión inmediata de que ciertas proposiciones son verdaderas: "Al contrario, es nuestro actuar lo que yace en el fondo del juego de lenguaje". En otro lugar asegura que tales creencias "constituyen el fundamento de la acción, y por tanto, también del pensamiento". Más aun, tales pseudoproposiciones muestran lo que Wittgenstein llama "imagen del mundo", imagen que es el sustrato de todas las investigaciones y afirmaciones de los sujetos que la comparten, fondo en el que se recorta lo que se considera verdadero o falso, correcto o incorrecto. En algún momento, a ese tipo de proposiciones y la imagen del mundo que conforman se las equipara "a una suerte de mitología" cuya "función es semejante a la de las reglas de juego". Tal imagen del mundo se adquiere cuando nos hacemos competentes en el uso de la lengua de la comunidad a la que pertenecemos, pues no adquirimos creencias una a una, discretamente consideradas, sino una compleja red de creencias que se 
apoyan unas a otras. Aun más, aprendiendo así un lenguaje-en-uso, aprendemos todo un canon epistemológico: cuáles son las fuentes autorizadas de conocimiento, quiénes tienen autoridad, qué formas debe revestir la experiencia, qué asuntos son susceptibles de ponerse en duda y qué dudas me harían perder un sentido compartido con el resto de hablantes, qué se considera una buena razón, etc. El caso es que esas creencias que conforman una imagen del mundo son, piensa Wittgenstein, como el lecho rocoso sobre el que discurren los enunciados propiamente empíricos. Ello no quiere decir, como también subraya, que ese lecho rocoso permanezca inalterable: el discurrir de la corriente lo transformará y en unas ocasiones las proposiciones empíricas se solidificarán y formarán parte del lecho, mientras que en otras las que conforman el lecho se diluirán y se integrarán al torrente. En todo caso, "las proposiciones que la describen [la imagen del mundo] no están todas sometidas del mismo modo a la comprobación" (Wittgenstein, 1988: \$94-97, $\$ 99, \$ 162, \$ 204, \$ 401$ y $\$ 411)$.

Cuando Wittgenstein pone ejemplos de ese tipo de proposiciones pseudoempíricas integrantes de la imagen del mundo, sus ejemplos son del tipo "sé que tengo dos manos", "el mundo no ha empezado a existir hace cinco minutos", "los gatos no nacen de los árboles", es decir, aluden al mundo de la naturaleza. ${ }^{3}$

\footnotetext{
${ }^{3}$ No soy inconsciente de los problemas que implica considerar el enunciado "la diferencia sexual se expresa entre los javaneses como una variedad doméstica del estatus" como una de las proposiciones pseudoempíricas. Entre otras razones, porque Wittgenstein califica así enunciados de corte muy diferente, por ejemplo: "Sé que tengo dos manos" — cuando se profiere en un contexto cotidiano normal, no pongamos por caso en una situación postraumática- o "Existen los objetos físicos". La diferencia que quiero señalar radica en que mientras el primer enunciado puede ser proferido por cualquiera que hable español, el segundo es un enunciado propio de un filósofo en el contexto de ciertas discusiones filosóficas para describir una certeza en la acción de los hablantes del español. El enunciado "La diferencia sexual se expresa entre los javaneses como una variedad doméstica del estatus" - en el que el antropólogo ocupa el lugar del filósofosería análogo a "Existen objetos físicos" por cuanto describe la certeza supuesta en toda acción por la comunidad lingüística de los javaneses.
}

Pero nada impide ampliar el rango de sus tipos. En otro lugar he defendido que las proposiciones que expresan creencias mágicas y religiosas tienen ese carácter (Sánchez Durá, 1993). También pueden incluirse aquellas que aluden al sentido que tiene la vida para los miembros de una comunidad. Ya Peter Winch afirmó que no puede dilucidarse cómo concibe una sociedad un concepto formal tan abstracto como el de "coherencia" si no es teniendo en cuenta el sentido que de la vida tienen aquellos que siguen un particular sistema de reglas lingüísticas (Winch, 1964).

\section{A DROP OF PRAGMATISM}

Hasta aquí he usado la noción de "comunidad lingüística" o de "comunidad de hablantes" de una manera laxa, pero de nuevo pueden hacerse consideraciones de índole pragmática. En ciertas ocasiones habrá que entender por "comunidad lingüística" a los hablantes de una lengua natural en un determinado periodo o a los hablantes de las lenguas con y sin escritura, o aun a los hablantes que comparten dentro de una lengua natural un conjunto coordinado de usos que no comparten los otros hablantes de esa lengua. En cada una de esas delimitaciones podremos discernir un tipo de creencias como las que pertenecen a la noción wittgensteiniana de imagen del mundo. Pero, insisto, esas delimitaciones estarán determinadas por consideraciones pragmáticas debidas a los intereses particulares del estudioso, entre los cuales el principal debe ser captar la intrincada malla de diferencias culturales como hoy se presenta, y también los múltiples sentidos de pertenencia que los individuos tienen. Geertz hizo una observación en ese sentido cuando criticó los universales culturales. Señaló que de poco vale dedicarse a discernir rasgos culturales empíricamente universales si no son relevantes por su contenido y no meras abstracciones vacías (Geertz, 1990: 43 y ss.): 
La cuestión no es [...] si en el funcionamiento de sus mentes [de los hombres] existen unos rasgos comunes que sean independientes del lugar en el que viven (los papúes sienten envidia, los aborígenes sueñan)... Lo importante es cómo podemos utilizar estas cualidades indubitables a la hora de explicar rituales [...] o comparar lenguas (Geertz, 1996b: 95 y ss.).

De modo que es perfectamente posible formular la tesis del relativismo cultural en tanto es posible considerar diversos marcos de relativización cultural. Cuestión relativamente diferente es el tercer aspecto involucrado en la formulación de todo relativismo: la radicalidad con la que se relativiza algo respecto de los ámbitos culturales que decidamos identificar según nuestros intereses teóricos y prácticos. Este aspecto es el que decide que el relativismo cultural sea un desatino de impredecibles consecuencias morales y políticas o un saludable antídoto contra otras calamidades morales y políticas que provienen del retorno del etnocentrismo bajo uno de sus rostros posibles. Creo que lo que subyace a las polémicas sobre el relativismo cultural es una cuestión no tanto epistemológica sino axiológica (Geertz, 1992): la diferencia entre los que piensan que "las ciencias humanas" deben desarrollarse en tanto técnica cada vez más sofisticada de control social y los que plantean que deberían dedicarse a posibilitar una mayor habilidad y mejor sentido para vivir nuestras vidas. Esto nos trae de nuevo al narcisismo cultural, que no habla de jerarquías o exclusiones radicales, pero

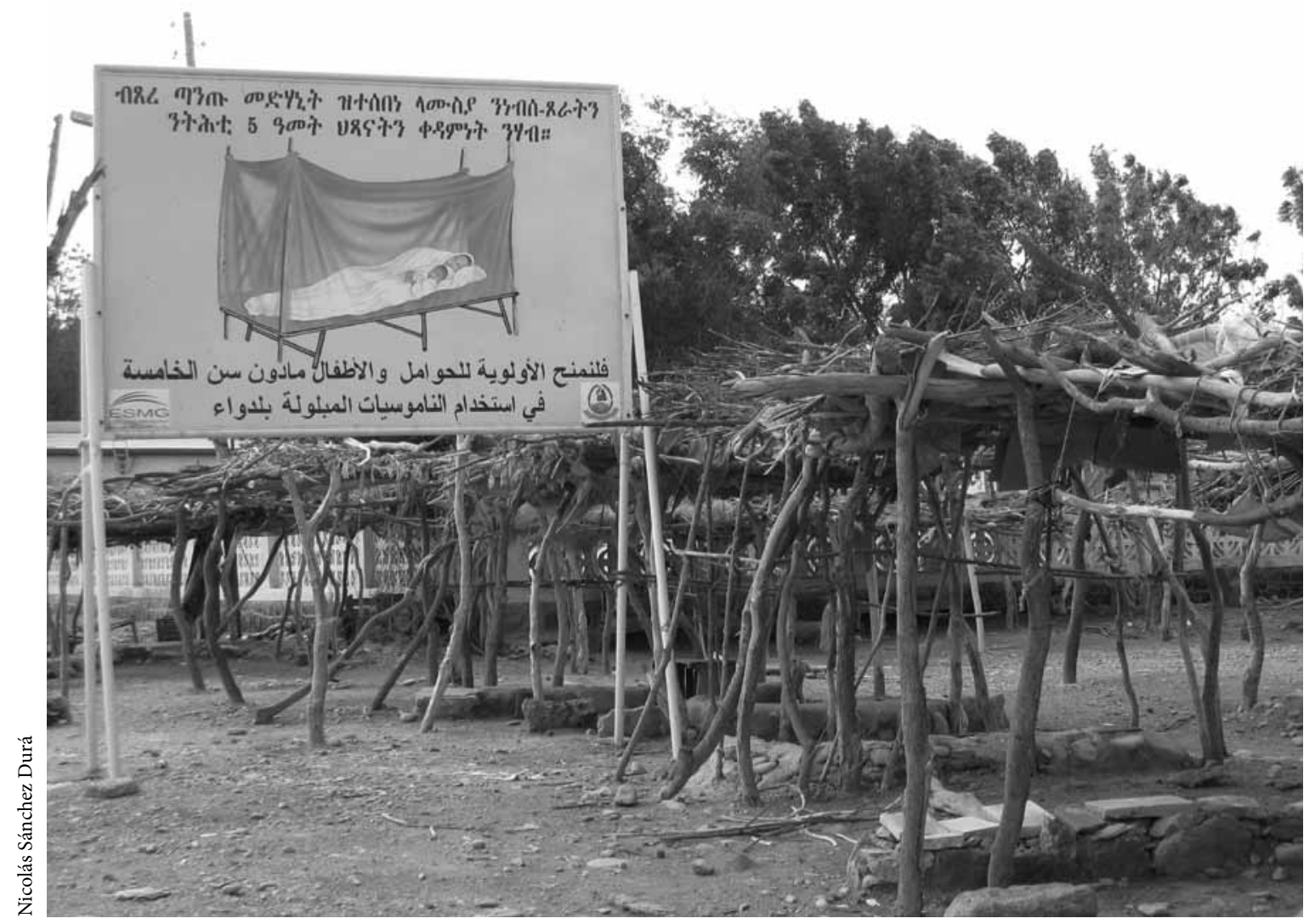

Cartel gubernamental escrito en amárico y árabe para extender el uso de mosquiteras en prevención de la malaria. Mercado de Foro, Golfo de Zula, Eritrea, 2011. 
que sí merece considerarse como una nueva variedad de etnocentrismo, de polietnocentrismo.

Con todo, algunas distinciones conceptuales previas son convenientes. $\mathrm{Al}$ tratar las diferencias culturales suelen confundirse dos aspectos. Cuando se habla de la igualdad de derechos y de la dignidad de los pueblos, la cuestión es jurídica y ética; cuando se subrayan las diferencias culturales, la cuestión es histórica y antropológica. Ambos aspectos pueden involucrar políticas indeseables: el asimilacionismo en un caso, o el "narcisismo de la diferencia menor" en el otro. ${ }^{4}$ El principio ético-político de la igualdad implica subrepticiamente a menudo la hipótesis antropológica de la identidad, que fácilmente se ha traducido en una política asimilacionista (Todorov, 2002: 139 y ss.). Lo veíamos en el caso de Las Casas. Por otra parte, la insistencia en las diferencias puede desembocar en la magnificación de lo pequeño, y favorecer así el olvido de lo común. En cualquier caso, nuestro mundo hoy no está formado por unidades culturales homogéneas bien discernidas con

una tolerancia indiferente y autosatisfecha unas respecto de otras. Lo que estamos viviendo - por decirlo con una intención distinta a la de Rorty- son comunidades que se dedican cada vez más a hacer apología de sus héroes y a satanizar a sus enemigos. Es, por tanto, un mundo en el que el grado de hostilidad e intolerancia entre los grupos no tiene, en ocasiones, una relación directa con la magnitud de las diferencias culturales e históricas o en el que las diferencias se resignifican y se magnifican por el mero hecho de su reivindicación violenta. Es decir, es un mundo donde las relaciones de poder, en una dirección u otra, "agrandan lo pequeño" y el ensimismamiento identitario como una forma de resistencia, o bien avalan políticas de exclusión y dominio.

De ahí que el nuevo etnocentrismo como narcisismo cultural, por lo menos desde el punto de vista del discurso antropológico, deba evitarse. Es decir,

${ }^{4}$ Término de origen freudiano rescatado para aplicarlo al análisis de los nuevos conflictos nacionalistas de la posguerra fría (Ignatieff, 1999). hay que mantener los dos aspectos mencionados —el ético-político y el histórico-etnológico- a la vista en su tensión ineludible y considerar las diferencias en un marco de interpretación igualitario. No es fácil ni existe una fórmula para todos los contextos. Por eso el relativismo más que una tesis teórica es una actitud pragmática y moral recomendable. Debemos seguir estudiando la diversidad cultural para captar el sentido que tiene creer, valorar y comportarse de muchas otras maneras, porque el problema de este tipo de etnocentrismo no es tanto que nos encierre en nuestras preferencias, sino que sigue impidiendo descubrir nuestra manera de ser y su eventual cambio en sensibilidades y modos de pensamiento diferentes, aunque éstos nunca lleguen a ser nuestros. Son precisamente las asimetrías entre nosotros y los otros lo que permite situarnos de una manera en el mundo, hacernos mutuamente visibles y poder valorar lo que queremos y lo que no queremos ser, lo que nos permite imaginar otras maneras de ser (Geertz, 1996b).

Además, el narcisismo cultural sigue considerando a las sociedades como unidades culturales homogéneas y uniformes según un modelo configurativo de cultura. Es obvio que no sólo nuestras sociedades, sino todas las del mundo contemporáneo - aunque ciertamente hay diferencias de grado muy notables- están recorridas por muy diferentes sentidos de pertenencia, que no son constantes temporal ni espacialmente, sino discontinuos, atravesados por múltiples líneas de fractura. El narcisismo cultural, considerado no ya desde un punto de vista moral sino epistemológico, impide distinguir los elementos constitutivos de cada sociedad, ver de dónde proceden, el sentido que pudieron tener y cómo se relacionan unos con otros formando esas complicadas mallas culturales que recorren el mundo de forma discontinua, lo cual es de especial significación para la lógica de la identidad en las sociedades modernas sometidas a una veloz licuefacción de todos los vínculos. En ellas las identidades de los individuos andan siempre under construction: son transitorias, considerablemente optativas y se rigen 
por una lógica experimental según una racionalidad de fines (Bauman, 2005). En definitiva, como defendió Geertz, debemos proseguir la tarea de captar lo ajeno sin vaciarlo de contenido hablando de inmediato de una humanidad común, sin despreciarlo $a b$ initio con una actitud indiferente o considerándolo algo exótico pero absurdo. Todo ello constituye el impulso que - unas veces más, otras menos - siempre ha latido bajo la actitud relativista. El etnocentrismo, en tanto narcisismo cultural, inhibe la posibilidad de cambiar. La historia de los pueblos, y también la de las personas, ha sido la historia del cambio de sus concepciones sobre la vida y de la crítica de sus propias tradiciones culturales. Por tanto, la consideración de la diversidad cultural debe consistir menos en diferenciarnos de los otros para defender la integridad y la lealtad al grupo que en definir el terreno que la razón debe cruzar con el fin de entrar en contacto con las variantes de la subjetividad y de la sociedad. Ése fue el proyecto por el que propugnó Geertz en toda su obra. Ese proceso de crítica y de cambio ha sido mayor en las tradiciones culturales con fuertes componentes ilustradas, pero tal tradición no puede improvisarse ni imponerse.

Para acabar, dos cuestiones: una de índole teórica, la otra de índole política. Dije que de la radicalidad con la que se relativiza algo respecto de las culturas que decidamos identificar podían derivar verdaderos desatinos. Desde la óptica que he defendido lo que debería preocuparnos es la comunicabilidad, dado que se trata de hablar con los otros, de comprender otras formas de vida y, en su caso, llegar a sugestiones, transacciones y acuerdos. Pues bien, la comunicabilidad queda garantizada desde un relativismo moderado porque la inconmensurabilidad de los lenguajes siempre es parcial (Kuhn, 1989). Lo que plantea problemas de interpretación siempre es un "hueso duro" que no se deja traducir. Pero la metáfora de la comprensión en cuanto traducción ha generado obstáculos epistemológicos que pueden disolverse de tener en cuenta que podemos comprender cosas que estrictamente no podemos traducir (Sánchez Durá, 1994). En la medida en que las comprendamos y queramos introducirlas por medio de parafraseos en un lenguaje donde no se generaron, es decir, cuando se trate de traducción por innovación y no por repetición, habrá que cambiar inevitablemente el lenguaje-en-uso de la comunidad lingüística que ejerce de anfitriona de manera que devenga otro lenguaje-en-uso (MacIntyre, 1994: 355 y ss.). Esto deja teóricamente a salvo la posibilidad de que diferentes tradiciones culturales entren en contacto y refuerza el hecho de que sigamos valorando las ventajas de un relativismo cultural moderado. Los más capacitados para comprender la verdad que conlleva, y los más inmunizados contra sus excesos, serán los individuos familiarizados con las más dispares tradiciones culturales.

Insisto, no creo que los problemas sean hoy preferentemente de índole teórica, sino morales y políticos. En cuanto el sistema colonial entró en bancarrota y aparecieron nuevos sujetos políticos en el panorama internacional, a partir de la Segunda Guerra Mundial, la antropología fue abandonando de manera desigual aquel modelo objetivante de perfume positivista a partir del cual el otro era descrito desde una exterioridad radical. Empezó a prevalecer una antropología hermenéutica dedicada a captar los sistemas de creencias y de significado, las formas de vida, las culturas, etc., pero intentaba captarlos de una manera especial, comprenderlos desde el punto de vista de los "otros", "ver" como los otros veían, y todo bajo la perspectiva de una conversación efectiva o posible. Creo que en el campo de la filosofía Peter Winch fue uno de los pioneros y no ha recibido el reconocimiento que merece. En el ámbito de la filosofía anglófona, fue el momento de la ácida polémica contra el relativismo. Aquel relativismo, a pesar de expresarse en polémicas onto-epistemológicas, estaba más motivado por un impulso moral y político anticolonial. Como ha afirmado Shweder, el relativismo, queriendo escapar de un universalismo abstracto eurocéntrico, pretendía a fin de cuentas "dar permiso a la diversidad cultural” (Shweder, 1989: 99). 


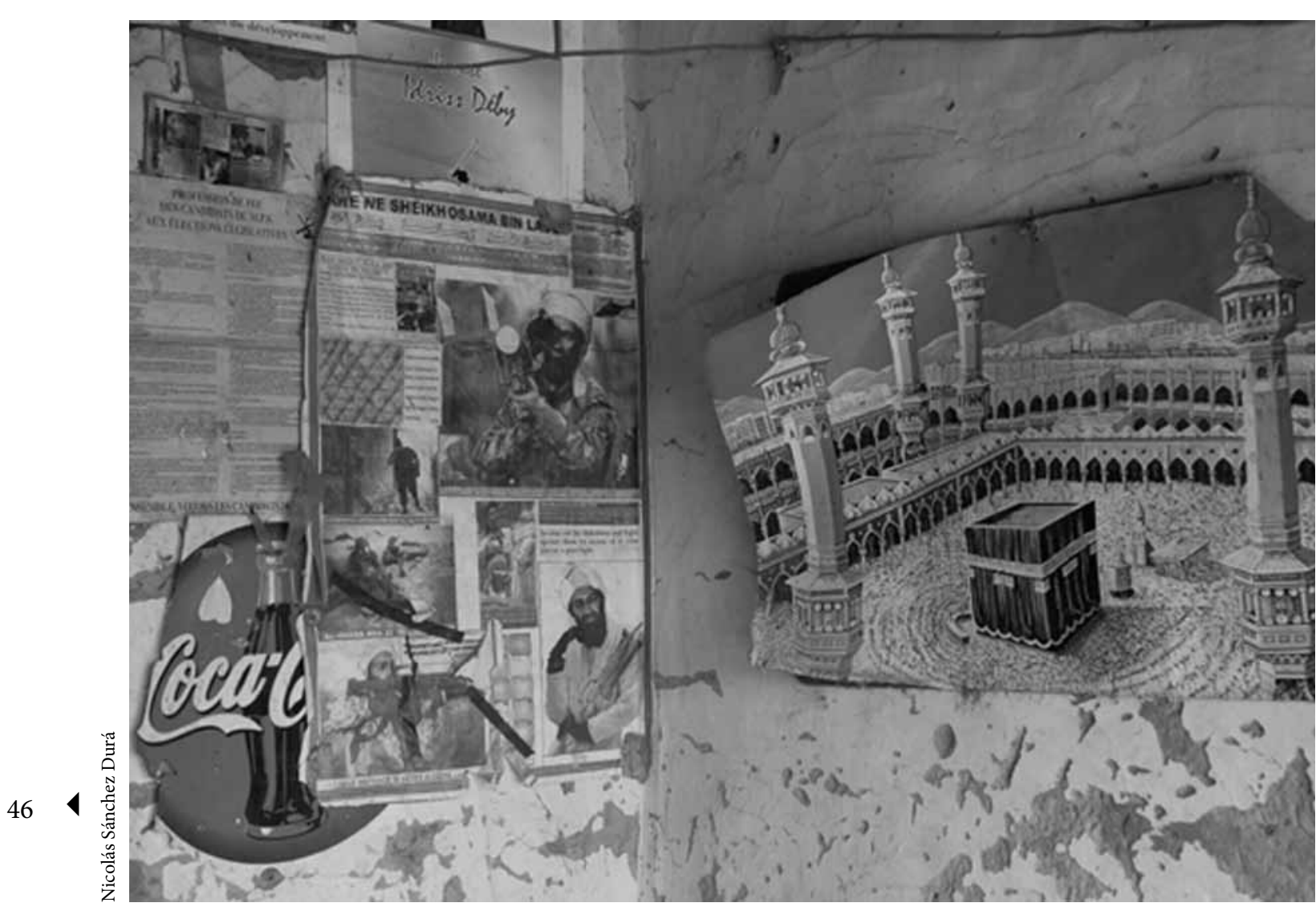

Carteles en el interior de una tienda en Cheddra, región de Kanem, Chad, 2005.

Esto no impide reconocer la patente restricción de lo que consideramos digno de ser aceptado como "una buena razón". Hay clases enteras de razones que no estamos dispuestos a aceptar porque dependen de conocimientos, de hechos que hemos aprendido en ámbitos diversos. Si renunciáramos a ellos, todo nuestro mundo saltaría por los aires. No podemos aceptar que las desigualdades heredadas existen porque son el resultado del castigo y la recompensa por nuestros actos en una vida anterior o que las mujeres deben vivir apartadas durante la menstruación porque son impuras. Esas razones inaceptables están aquí y allá, conviven con otras de clase diferente y, en función de la multipertenencia cultural, los individuos las exhiben en unos contextos u otros. Es más, en una misma sociedad sus integrantes pugnan entre sí por imponer prácticas y creencias de distinto signo y aceptabilidad. Hasta en la más remota casa-racimo lobi, al sur de Burkina Faso, cerca de la frontera con Ghana, pude encontrar en la habitación de la esposa principal los carteles de las campañas del lejano gobierno de Uagadugu contra las mutilaciones femeninas y para la prevención del Sida. Lo significativo es que, cuando llegué allí una mañana, toda aquella extensa familia estaba reunida junto al altar de los fetiches practicando un oráculo con pollos para "saber" si la reciente muerte de uno de sus miembros había sido por brujería. Aquello me produjo una mueca de ironía y me hizo pensar, porque era prácticamente igual al descrito por Evans-Pritchard en Magia, brujería y oráculos entre los azande del que tanto se discutió en los años 
setenta y ochenta para decidir acerca de la racionalidad de los mismos y, por extensión, de los "primitivos". Por decirlo con Wittgenstein: el mismo "salvaje" que aparentemente traspasa la imagen de su enemigo para matarlo, construye su choza de madera y afila su flecha, no la efigie de su flecha.

Lo que ocurre es que en toda comunidad no es que unos traspasen imágenes de indeseables y otros hagan chozas de madera, sino que todos hacemos lo uno y lo otro. La urgencia ante la que nos encontramos no es saber si el sistema de valores que consideramos propio es o no universal, si es deseable universalizarlo, sino cómo asegurar las condiciones políticas que hagan posible una reflexión crítica desde un punto de vista intercultural. Afirmada la racionalidad de todos - aunque siempre hay lugar para el absurdo colectivo y privado-, eliminadas ciertas clases de razones a las que ya no reconocemos capacidad justificadora, todavía queda por determinar lo correcto, lo bueno y sus formas en una perspectiva pluralista acerca de qué es una vida buena. En ello debemos estar todos. Pero asegurar la participación simétrica en la conversación, siquiera tendencialmente, no es sólo una cuestión de qué tipo de discurso debe ser el propio de la antropología -objetivante, conversacional o coral y polifónico-, sino de la efectiva capacidad de intervenir en la conversación para que las diferentes voces surtan efectos apreciables. En esa vía, el ir y venir no arrojará más que consensos temporales, siempre parciales, a la vez que desacuerdos razonables. En cualquier caso, nada será posible si, allá al fondo, no sigue latiendo una actitud relativista, es decir, cierto escepticismo sobre lo propio.

\section{Referencias bibliográficas}

Bauman, Zygmunt, 2005, Identitat: converses amb Benedetto Vecchi, Universidad de Valencia, Valencia.

Césaire, Aimé, 2006, Discurso sobre el colonialismo, Akal, Madrid.

Chartier, Roger, 1985, “Text, Symbols, and Frenchness”, en The Journal of Modern History, vol. 57, núm. 4.
Clifford, James, 1986, "Introduction: Partial Truths", en George E. Marcus, Mike Fortun y Kim Fortun (eds.), Writing Culture. The Poetics and Politics of Ethnography, University of California Press, Berkeley.

Condorcet, 1980, Bosquejo de un cuadro histórico de los progresos del espiritu humano, Editora Nacional, Madrid.

Contat, Nicolas, [1762] 1980, Anecdotes tipographiques: où l'on voit la description des coutumes, mours et usages singuliers des compagnons imprimeurs, Oxford $\mathrm{Bi}-$ bliographical Society, Oxford.

Darnton, Robert, 1984, The Great Cat Massacre and Other Episodes in French Cultural History, Basic Books, Nueva York.

, 1987, La gran matanza de gatos y otros episodios en la historia de la cultura francesa, Fondo de Cultura Económica, México.

Evans-Pritchard, Edward, 1976, Brujería, magia y oráculos entre los azande, Anagrama (Biblioteca Anagrama de Antropología), Barcelona.

Feyerabend, Paul, 1996, "Contra la inefabilidad cultural. Objetivismo, relativismo y otras quimeras", en Salvador Giner y Scartezzini (eds.), Universalidad y diferencia, Alianza Universidad, Madrid.

Geertz, Clifford, 1990, La interpretación de las culturas, Gedisa, Barcelona.

_ 1992, “Local Knowledge' and its Limits: Some Obiter Dicta", en The Yale Journal of Criticism, vol. 5, núm. 5.

— 1996a, Tras los hechos. Dos países, cuatro décadas y un antropólogo, Paidós, Barcelona.

, 1996b, "Anti-antirrelativismo", en Clifford Geertz, Los usos de la diversidad, Paidós, Barcelona.

— 2002, Reflexiones antropológicas sobre temas filosóficos, Paidós, Barcelona.

Hegel, Georg Willhelm Friedrich, 1965, Die Vernunft in der Geschichte, Plon, París.

Ignatieff, Michael, 1999, El honor del guerrero. Guerra étnica y conciencia moderna, Taurus, Madrid.

Kuhn, Thomas, 1989, "Conmensurabilidad, comparabilidad y comunicabilidad”, en Thomas S. Kuhn, Qué son las revoluciones científicas y otros ensayos, Paidós, Institut de Ciències de l'Educació, Universidad Autónoma de Barcelona, Barcelona, Buenos Aires, México.

Las Casas, Bartolomé de, 1988a, Argumentum apologiae, en Fray Bartolomé de Las Casas. Obras completas, vol. 9, Ángel Losada (ed.), Alianza Editorial, Madrid.

1988b, Apologética Historia Sumaria, en Fray Bartolomé de Las Casas. Obras completas, vol. 8, Ángel Losada (ed.), Alianza Editorial, Madrid. 
Lévi-Strauss, Claude, 1993, "Raza y cultura”, en Raza y cultura, Cátedra, Madrid.

MacIntyre, Alasdair, 1994, Justicia y racionalidad, Ediciones Internacionales Universitarias, Barcelona.

Putnam, Hilary, 1983, “Two Dogmas Revisited”, en Hilary Putnam, Realism and Reason, Philosophical Papers III, Cambridge University Press, Cambridge.

Rosaldo, Renato, 1991, Cultura y verdad. Nueva propuesta de análisis social, Grijalbo, México.

Sánchez Durá, Nicolás, 1993, "Una explicación no tranquilizará al enamorado”, en Vicente Sanfélix (ed.), Acerca de Wittgenstein, Pre-textos, Valencia.

— 1994 , "Miradas fulgurantes y traductores caritativos”, en Julián Marrades y Nicolás Sánchez Durá (eds.), Mirar con cuidado. Filosofía y escepticismo, Pre-textos, Valencia.

-, 1996, "Soberbia, racionalidad y sujeto en el discurso antropológico clásico", en Manuel Cruz (ed.), Tiempo de subjetividad, Paidós, Barcelona.
1997, “Gauguin, Conrad y Leris, un episodio en la invención de la identidad primitiva”, en Vicente Sanfélix (ed.), Las identidades del sujeto, Pre-textos, Valencia.

, 1998, ¿El artista como etnógrafo?: el caso Gauguin, tan lejos, tan cerca, Episteme, Valencia.

Shweder, Richard, 1989, "Post-Nietzschean Anthropology: the Idea of Multiple Worlds", en Michael Krausz (ed.), Rationality: Interpretation and Confrontation, Notre Dame, Indiana.

Todorov, Tzvetan, 2002, Deberes y delicias, Fondo de Cultura Económica, Buenos Aires, México.

Traverso, Enzo, 2003, La violencia nazi. Una genealogía europea, Fondo de Cultura Económica, México.

Winch, Peter, 1964, "Understanding a Primitive Society", en American Philosophical Quarterly, núm. 1.

Wittgenstein, Ludwig, 1988, Sobre la certeza, Gedisa, Barcelona. 